\title{
Harm Reduction: A Research Agenda
}

\author{
Shannon Dea ${ }^{1} \cdot$ Daniel Weinstock ${ }^{2}$
}

Accepted: 22 October 2020 / Published online: 3 November 2020

(c) Springer Science+Business Media, LLC, part of Springer Nature 2020

This special issue of Health Care Analysis is part of a larger effort to engage philosophers and political theorists in the study of Harm Reduction (HR) and to encourage scholars and front-line workers who work within the HR tradition to look to philosophy and political theory for conceptual and theoretical resources. The initiative comes surprisingly late. HR has existed under that moniker for 30 years, and has become a globally influential public health approach. However, there has been surprisingly little engagement with HR by philosophers and political theorists, and there exists comparatively little transdisciplinary and transsectoral work on HR involving philosophers and political theorists. We hope to change that.

HR describes a broad approach that emerged in response to the HIV crisis in the 1980s. Earlier public health approaches to drug use emphasized abstinence and abolition. Recall, for instance, the U.S.'s "War on Drugs", and Nancy Reagan's notorious "Just Say No" campaign $[1,2]$. In combination, these two campaigns cast drug use as a legal and moral matter rather than a public health concern. Abstinence- and prohibition-based approaches proved disastrous in the face of the AIDS epidemic. Ronald Reagan did not publicly address AIDS until 1987 [3], well into his second term and four years after the World Health Organization began holding meetings about AIDS. By then, more than 20,000 Americans had died of the disease.

In stark contrast with this approach, HR pioneers in Merseyside (in parallel with similar initiatives in the Netherlands, Canada and Australia) sought to quickly reduce the spread of HIV not by reducing drug use but by reducing the vectors for disease transmission-primarily dirty needles and unprotected sex. HR volunteers and workers - many of them drug users themselves-provided clean needles, gear

Shannon Dea

Shannon.Dea@uregina.ca

Daniel Weinstock

Daniel.Weinstock2@mcgill.ca

1 Department Philosophy, Faculty of Arts, University of Regina, 3737 Wascana Parkway, Office CL426, Regina, SK S4S 0A2, Canada

2 Katharine A. Pearson Chair in Civil Society and Public Policy, Faculty of Law and Department of Philosophy, McGill University, New Chancellor Day Hall, Office 505, 3644 Peel St., Montreal, QC H3A 1W9, Canada 
cleaning kits, condoms, and safe sharps disposal, as well as targeted health education resources [4].

Since the early days of supporting safer drug use and safer sex to reduce HIV transmission, the HR approach has been expanded into a wider range of supports for a wider range of high risk behaviours. Notably, while HR originated in grassroots community-based initiatives, in many countries, it has become the default approach to public health and is led by nurses and social workers rather than (or in addition to) drug users, often with government funds. In Canada in the last decade, principles of HR have arguably grounded important Supreme Court decisions in support of safe injection sites, the legalization of prostitution, and medical assistance in dying. ${ }^{1}$

Despite these successes, HR has not often made its way into mainstream scholarship in political theory and philosophy. In 2013, we (the co-editors of this special issue) began to discuss this gap, which we were each seeking to address in our own work. Those discussions culminated in workshops and panel discussions in the United Kingdom at the University of Manchester and in Canada at McGill University, University of Waterloo and the University of British Columbia, in the creation of the Canadian Harm Reduction Theory (CHaRT) Network, and in the preparation of this special issue.

In those meetings and for this issue, we invited scholars from a range of disciplines broadly cognate with political theory and philosophy to offer their visions of and approaches to the political theory and philosophy of harm reduction. The resulting collection gathers together 13 short articles that, variously, (1) seek to provide high level conceptual analysis of just what HR is and how it works with the aim of extending its domain of application beyond traditional risky or controversial practices and behaviours (Dea and Weinstock), (2) explore the ethical and meta-ethical dimensions of HR (King, Hoffman, Stoljar, Kirschenheiter and Corvino), (3) assess HR in the context of particular policy domains already associated with HR (Porter, Viens and Coggan, Narváez-Chicaíza, Klein), and (4) apply HR to novel harms (Jones, Gruenewald, Shields). We think that the varied and stimulating scholarship our call elicited reveals the enormous potential for the political theory and philosophy of harm reduction as an avenue for further inquiry.

As we write this, we note the now-surprising absence from the issue of discussions of HR approaches to COVID-19. In the Fall of 2020, as the world grapples once again with the question of how best to respond to an aggressive disease with no vaccine, we are increasingly hearing HR-style proposals. Some scholars (including one of the editors of this collection) [4] and public health advocates argue that a moralistic, all-or-nothing approach to the Coronavirus grounded in calls for abstinence and in massive use of the state's law enforcement powers is unrealistic and untenable, and advocate for an HR approach that seeks to reduce the worst risks associated with the pandemic via a more flexible, sustainable, and non-judgmental

\footnotetext{
1 Canada (Attorney General) v. Bedford. 2013 SCC 72, [2013] 3 SCR 1101.

Canada (Attorney General) v. PHS Community Services Society. 2011 SCC 44, [2011] 3 SCR 134.

Carter v. Canada (Attorney General). 2015 SCC 5, [2015] 1 SCR 331.
} 
approach. Other scholars [5] draw explicit analogies between the AIDS crisis of the 1980s and the current pandemic, with attendant HR lessons.

This issue does not include robust discussion of HR approaches to COVID 19 because the papers were written just before the disease landed in North America, where most of the authors are based. However, the lessons we are quickly learning from the pandemic - and those that members of the public are finding difficult to learn - reinforce for us what initially drew us to this topic. Namely, in its first 30 years, HR has established itself as a powerful mode of intervention, one that is deeply intuitive (if still controversial), and a versatile one that is susceptible of rapid, highly effective applications well beyond the domain in which it initially emerged. Now more than ever, philosophers and political theorists who are committed to understanding and mitigating the most serious harms we face ought to take up the study of HR as a powerful modality in that project.

\section{References}

1. White, A. (2004). Reagan's AIDS legacy/silence equals death. In SFGate Jan 27, 2012.

2. Zigon, J. (2018). A war on people: Drug user politics and a new ethics of community. Oakland: University of California Press.

3. O'Hare, P. (2007). Merseyside, the first harm reduction conferences, and the early history of harm reduction. International Journal of Drug Policy, 18(2), 141-144.

4. Weinstock, D. (2020). A harm reduction approach to the ethical management of the COVID-19 pandemic. Public Health Ethics. https://doi.org/10.1093/phe/phaa026.

5. Kutscher, E., \& Greene, R. E. (2020). A harm reduction approach to coronavirus disease 2019. JAMA Health Forum. https://doi.org/10.1001/jamahealthforum.2020.0656.

Publisher's Note Springer Nature remains neutral with regard to jurisdictional claims in published maps and institutional affiliations. 